\section{$\underset{\substack{\text { hommes } \\ \text { \& migrations }}}{ }$}

\section{Hommes \& migrations}

Revue française de référence sur les dynamiques

migratoires

1334 | 2021

Exposer le racisme et l'antisémitisme

\title{
Mansour Fahmy, La condition de la femme dans l'islam
}

Paris, Allia, 2021, 158 p., $10 €$.

\section{Mustapha Harzoune}

\section{Q OpenEdition}

\section{Journals}

\section{Édition électronique}

URL : https://journals.openedition.org/hommesmigrations/13133

DOI : 10.4000/hommesmigrations. 13133

ISSN : 2262-3353

\section{Éditeur}

Musée national de l'histoire de l'immigration

\section{Édition imprimée}

Date de publication : 1 juillet 2021

Pagination : 231

ISBN : 978-2-919040-58-2

ISSN : 1142-852X

\section{Référence électronique}

Mustapha Harzoune, "Mansour Fahmy, La condition de la femme dans l'islam », Hommes \& migrations [En ligne], 1334 | 2021, mis en ligne le 01 juillet 2021, consulté le 04 février 2022. URL : http:// journals.openedition.org/hommesmigrations/13133; DOI : https://doi.org/10.4000/ hommesmigrations.13133 


\section{La condition de la femme dans l'islam}

Mansour Fahmy, Paris, Allia, 2021, 158 p., $10 €$

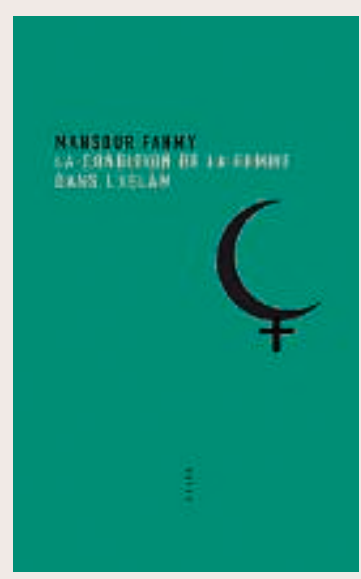

Voici une thèse soutenue à la Sorbonne en... 1913! Pour ce travail, l'auteur fut injurié, persécuté, soumis à la censure par les cheikhs et autres journalistes. Il dut attendre six ans pour être réintégré à l'université. Il faut dire que le propos était révolutionnaire. II l'est toujours! Mansour Fahmy étudie le statut de recluse des femmes dans l'islam. Pour ce faire, il utilise non pas les outils de l'exégèse, mais les armes de la sociologie, de l'histoire et de la psychologie. Et à quoi ou plutôt à qui applique-t-il sa méthode? Au prophète lui-même! Mansour Fahmy s'emploie à montrer comment son comportement

- sacralisé et imité par les croyants, et peut-être aujourd'hui plus encore qu'hier - influença la sévérité de l'islam à l'égard des femmes. Il affirme que la jalousie de Mohamed «devait [...] contribuer à la dégradation de la femme musulmane». Il ose écrire que la «sensualité anormale» du prophète - qui redoutait la tentation qu'un simple regard parvenait à éveiller est à l'origine de la «diabolisation» de la femme, partant de son exclusion!

Quant aux conditions sociohistoriques (évolution des mœurs, rapport de classe, extension de l'islam...), elles renforcèrent la réclusion et le port du voile au point que, en dépit d'une reconnaissance juridique nouvelle, « la femme post-islamique se trouve en fait dans une condition inférieure à celle de la femme anté-islamique».

Voilà de quoi bousculer une doxa contemporaine! On pense ici aussi aux travaux de Juliette Minces, amie et fidèle de la revue, qui vient de nous quitter.

Pour Mansour Fahmy, la réclusion et le port du voile sont l'expression d'un rapport de classe: le signe distinctif entre la femme libre (recluse et voilée!) et l'esclave (libre de ses mouvements et non voilée) puis, avec l'expansion de l'islam, entre la musulmane et la nonmusulmane. Les conquêtes se multipliant, le nombre des esclaves grimpa. De sorte que les rapports imposés par les hommes aux femmes esclaves (facilité des divorces et autres ménages polygames) imprimeront leurs marques sur «la situation de l'épouse et (les conceptions) qui se sont développées aux cours des siècles au sujet de la femme musulmane».

En 1913, Mansour Fahmy pensait voir arriver le temps de l'émancipation pour la femme musulmane. Son retour en Égypte a sans doute refroidi l'intellectuel. Pour Mohamed Harbi, auteur d'une préface écrite en 1990, le drame reste d'actualité: "Voilà qui en dit long sur la boue dans laquelle pataugent les sociétés arabes et leurs idéologues. » Seulement les sociétés dites arabes?

M. H. 